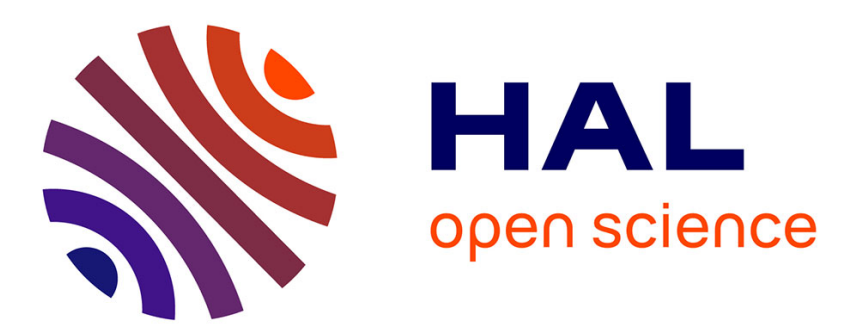

\title{
Effect of the Nd content on the structural and photoluminescence properties of silicon-rich silicon dioxide thin films
}

Olivier Debieu, Julien Cardin, Xavier Portier, Fabrice Gourbilleau

\section{- To cite this version:}

Olivier Debieu, Julien Cardin, Xavier Portier, Fabrice Gourbilleau. Effect of the Nd content on the structural and photoluminescence properties of silicon-rich silicon dioxide thin films. Nanoscale Research Letters, 2011, 6 (1), pp.1-8. 10.1016/j.nimb.2003.11.037 . hal-01139259

\author{
HAL Id: hal-01139259 \\ https://hal.science/hal-01139259
}

Submitted on 3 Apr 2015

HAL is a multi-disciplinary open access archive for the deposit and dissemination of scientific research documents, whether they are published or not. The documents may come from teaching and research institutions in France or abroad, or from public or private research centers.
L'archive ouverte pluridisciplinaire HAL, est destinée au dépôt et à la diffusion de documents scientifiques de niveau recherche, publiés ou non, émanant des établissements d'enseignement et de recherche français ou étrangers, des laboratoires publics ou privés. 


\title{
Effect of the $\mathrm{Nd}$ content on the structural and photoluminescence properties of silicon-rich silicon dioxide thin films
}

\author{
Olivier Debieu, Julien Cardin, Xavier Portier, Fabrice Gourbilleau*
}

\begin{abstract}
In this article, the microstructure and photoluminescence (PL) properties of $\mathrm{Nd}$-doped silicon-rich silicon oxide (SRSO) are reported as a function of the annealing temperature and the $\mathrm{Nd}$ concentration. The thin films, which were grown on Si substrates by reactive magnetron co-sputtering, contain the same Si excess as determined by Rutherford backscattering spectrometry. Fourier transform infrared (FTIR) spectra show that a phase separation occurs during the annealing because of the condensation of the $\mathrm{Si}$ excess resulting in the formation of silicon nanoparticles (Si-np) as detected by high-resolution transmission electron microscopy and X-ray diffraction (XRD) measurements. Under non-resonant excitation at $488 \mathrm{~nm}$, our Nd-doped SRSO films simultaneously exhibited PL from Si-np and $\mathrm{Nd}^{3+}$ demonstrating the efficient energy transfer between Si-np and $\mathrm{Nd}^{3+}$ and the sensitizing effect of Si-np. Upon increasing the $\mathrm{Nd}$ concentration from 0.08 to 4.9 at.\%, our samples revealed a progressive quenching of the $\mathrm{Nd}^{3+} \mathrm{PL}$ which can be correlated with the concomitant increase of disorder within the host matrix as shown by FTIR experiments. Moreover, the presence of Nd-oxide nanocrystals in the highest $\mathrm{Nd}$-doped sample was established by XRD. It is, therefore, suggested that the Nd clustering, as well as disorder, are responsible for the concentration quenching of the $\mathrm{PL} \mathrm{of} \mathrm{Nd}^{3+}$.
\end{abstract}

\section{Introduction}

Over the last decade, there has been an increasing interest toward nanomaterials for novel applications. One of the challenging fields concerns silicon-compatible light sources which are getting more and more attractive since they can be integrated to microelectronics devices [1]. Amorphous $\mathrm{SiO}_{2}$ is an inefficient host matrix for the photoluminescence (PL) of $\mathrm{Nd}^{3+}$ ions since, on the one hand, the absorption cross section of $\mathrm{Nd}$ is low $(1 \times$ $10^{-20} \mathrm{~cm}^{2}$ ) and, on the other hand, the Nd solubility in silica is limited by clustering $[2,3]$, which quenches the PL of the rare earth (RE) ions $[4,5]$. However, since the discovery of the sensitizing effect of silicon nanoparticles (Si-np) toward the RE ions [6], RE-doped $\mathrm{a}-\mathrm{SiO}_{2}$ films containing $\mathrm{Si}-\mathrm{np}$ are promising candidates for the achievement of future photonic devices. In such nanocomposites, $\mathrm{Nd}^{3+}$ ions benefit from the high absorption cross section of Si-np $\left(1-100 \times 10^{-17} \mathrm{~cm}^{2}\right)$ by an efficient

\footnotetext{
* Correspondence: fabrice.gourbilleau@ensicaen.fr

CIMAP, UMR CNRS/CEA/ENSICAEN/UCBN, Ensicaen 6 Bd Maréchal Juin, 14050 Caen Cedex 4, France
}

\section{SpringerOpen ${ }^{\odot}$}

(C) 2011 Debieu et al; licensee Springer. This is an Open Access article distributed under the terms of the Creative Commons Attribution License (http://creativecommons.org/licenses/by/2.0), which permits unrestricted use, distribution, and reproduction in any medium, provided the original work is properly cited. energy transfer mechanism, which enables the PL efficiency of RE ions to be enhanced by 3-4 orders of magnitude offering interesting opportunities for the achievement of future practical devices optically excited. In contrast to $\mathrm{Er}^{3+}$ ions [6-8], such materials doped with $\mathrm{Nd}$ have not been widely investigated and, accordingly, the energy transfer mechanism between $\mathrm{Si}$-np and $\mathrm{Nd}^{3+}$ ions, and its limitation [9-16]. Several authors have demonstrated that the energy transfer is more effective with small Si-np [10,11]. Seo et al. [11] have observed a decrease of the PL intensity of $\mathrm{Nd}^{3+}$ ions upon increasing the $\mathrm{Si}$ excess, i.e., increasing the Si-np average size. They concluded that only small Si-np which present excitonic states with a sufficient energy band-gap can excite the ${ }^{4} F_{3 / 2}$ level of $\mathrm{Nd}^{3+}$ ions. Several groups, which studied the effect of the Nd concentration in the PL properties of $\mathrm{Nd}$-doped $\mathrm{Si}-\mathrm{np} / \mathrm{SiO}_{2}$ demonstrated that the PL of $\mathrm{Nd}^{3+}$ ions is more efficient at low $\mathrm{Nd}$ concentration $[12,13]$.

The object of the present investigation is therefore to characterize the PL properties of nanostructured thin films containing a low concentration of Si excess as a 
function of the $\mathrm{Nd}$ concentration and the annealing temperature in relation with their microstructures. The $\mathrm{Nd}$-doped silicon-rich silicon oxide (SRSO) thin layers were synthesized by reactive magnetron co-sputtering. Their microstructures were examined using highresolution transmission electron microscopy (HRTEM), $\mathrm{X}$-ray diffraction (XRD), and Fourier transform infrared (FTIR) spectroscopy. We could notably establish the proper conditions to obtain efficient PL of $\mathrm{Nd}^{3+}$ but also describe its limitations.

\section{Experiment}

In this study, Nd-doped SRSO thin layers were deposited at room temperature on $p$-type $\mathrm{Si}$ wafers by a reactive magnetron RF co-sputtering method that consists in sputtering simultaneously a pure $\mathrm{SiO}_{2}$ target topped with $\mathrm{Nd}_{2} \mathrm{O}_{3}$ chips. The $\mathrm{Nd}$ content was monitored by the surface ratio between the $\mathrm{Nd}_{2} \mathrm{O}_{3}$ chips and the $\mathrm{SiO}_{2}$ target. The sputtering gas was a mixture of argon and hydrogen; the latter enables us to control the $\mathrm{Si}$ excess of the deposited layers by reacting with oxide species in the plasma [17]. The samples were subsequently annealed at high temperature ranging from 900 to $1100{ }^{\circ} \mathrm{C}$ in a dry nitrogen flow.

The composition of the deposited layers was determined by Rutherford backscattering spectrometry, while microstructural analyses were performed using of XRD and HRTEM on samples prepared in the cross-sectional configuration using a JEOL $2010 \mathrm{~F}(200 \mathrm{kV})$. The infrared absorption properties were investigated unsing a Nicolet Nexus FTIR spectrometer at Brewster's incidence.

Room temperature PL measurements were performed using an argon ion laser operating at $488 \mathrm{~nm}(7.6 \mathrm{~W} /$ $\mathrm{cm}^{2}$ ) as excitation source. This excitation wavelength is non-resonant with $\mathrm{Nd}^{3+}$ ions so that only an indirect excitation of $\mathrm{Nd}$ can occur $[13,15]$. The visible spectra were recorded using a fast photomultiplier (Hamamatsu) after dispersion of the PL with a Jobin-Yvon TRIAX 180 monochromator, while the infrared PL was measured using a Jobin-Yvon THR 1000 monochromator mounted with a cooled Ge detector and a lock-in amplifier to record the near-infrared spectra up to $1.5 \mu \mathrm{m}$.

\section{Results}

In this study, we were interested in four $\mathrm{Nd}$-doped SRSO thin films containing the same excess of $\mathrm{Si}$ (7 at.\%) with various $\mathrm{Nd}$ contents ranging from 0.08 to 4.9 at.\%.

\section{Microstructure}

Figure 1 shows the FTIR spectrum of the lowest Nddoped sample as-deposited and a fit with eight Gaussian peaks. Several bands characteristic of amorphous $\mathrm{SiO}_{2}$ are observed. The two prominent bands at 1236 (red), and $1052 \mathrm{~cm}^{-1}$ (blue) are assigned to longitudinal optical

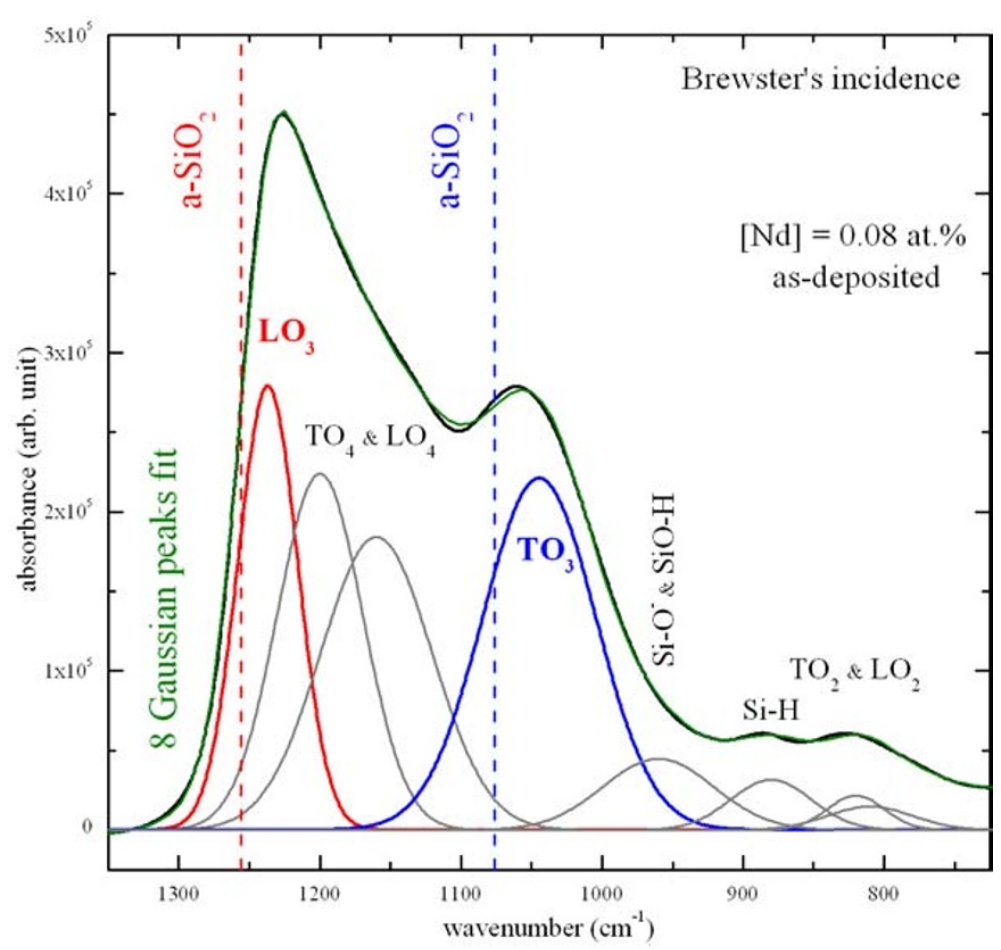

Figure 1 FTIR spectrum of the lowest $\mathrm{Nd}$-doped sample as-deposited 
$\left(\mathrm{LO}_{3}\right)$ and transverse optical $\left(\mathrm{TO}_{3}\right)$ phonons of $\mathrm{Si}-\mathrm{O}$ bonds, respectively. One can notice that these two bands are slightly shifted to lower wavenumbers compared to the stoichiometric positions of a- $\mathrm{SiO}_{2}$ at 1256 and $1076 \mathrm{~cm}^{-1}$, respectively. The $\mathrm{TO}_{2}, \mathrm{LO}_{2}, \mathrm{LO}_{4}$, and $\mathrm{TO}_{4}$ vibration modes are also present at $810,820,1160$, and $1200 \mathrm{~cm}^{-1}$, respectively. In addition to Si-O vibration modes, a weak absorption band centered at 880 $\mathrm{cm}^{-1}$ is observed. This peak, which is assigned to $\mathrm{Si}-\mathrm{H}$ bonds, disappears after annealing because of the hydrogen desorption.

Figure 2a shows the evolution of the positions of the $\mathrm{LO}_{3}$ and $\mathrm{TO}_{3}$ vibration modes, and the $\mathrm{LO}_{3} / \mathrm{TO}_{3}$ intensity ratio, as a function of the annealing temperature. One can observe that, while the annealing temperature was increased, the $\mathrm{TO}_{3}$ and $\mathrm{LO}_{3}$ peaks' positions progressively shifted to higher wavenumbers toward their respective stoichiometric positions. It is explained by the phase separation that results in the formation of $\mathrm{Si}-\mathrm{np}$ $[18,19]$. The increase of the $\mathrm{LO}_{3}$ band intensity (see Figure $2 \mathrm{~b}$ ) is related to the increase of the number of Si-O$\mathrm{Si}$ bonds at the $\mathrm{SiO}_{x} / \mathrm{Si}$-np interface $[19,20]$, i.e., the increase of the density of Si-np [21].

Figure 3 presents the evolution of the FTIR spectra of samples annealed at $1100{ }^{\circ} \mathrm{C}$ as a function of the $\mathrm{Nd}$ concentration. One can observe that the $\mathrm{LO}_{3}$ band intensity, which is constant at low $\mathrm{Nd}$ concentrations of 0.08 and 0.27 at.\%, significantly decreased while the $\mathrm{Nd}$ content was increased from 1.68 to 4.9 at.\%. This evolution contrasts with the one of the $\mathrm{TO}_{4}-\mathrm{LO}_{4}$ pair modes. Indeed, the $\mathrm{TO}_{4}-\mathrm{LO}_{4}$ intensity remains constant at low $\mathrm{Nd}$ concentrations of 0.08 and 0.27 at.\%, and then, it progressively increases with increasing $\mathrm{Nd}$ content. This demonstrates that the incorporation of $\mathrm{Nd}$ in the thin films generates disorder in the host $\mathrm{SiO}_{2}$ matrix.

Moreover, one can notice, in the spectrum of the highest Nd-doped sample, the emergence of two weak absorption peaks centered at 910 and $950 \mathrm{~cm}^{-1}$ which are assigned to asymmetric mode of $\mathrm{Si}-\mathrm{O}-\mathrm{Nd}$ bonds [22]. These peaks are located above a shoulder which can originate from $\mathrm{Si}^{-} \mathrm{O}^{-}$and $\mathrm{Si}-\mathrm{OH}$ phonons $[23,24]$. However, one can exclude the existence of the $\mathrm{Si}-\mathrm{OH}$ vibration mode after annealing because of the hydrogen desorption. The emergence of these two absorption peaks suggests that other phonons are also optically active in this spectral range.

In Figure 4 is depicted the XRD spectra of the lowest and highest $\mathrm{Nd}$-doped samples. In the former sample, one broad band corresponding to a- $\mathrm{SiO}_{2}$ is observed, while the pattern of the latter sample indicates the presence of additional phases. In the $27-32^{\circ}$ range, it shows various sharp peaks that are located above a broad band

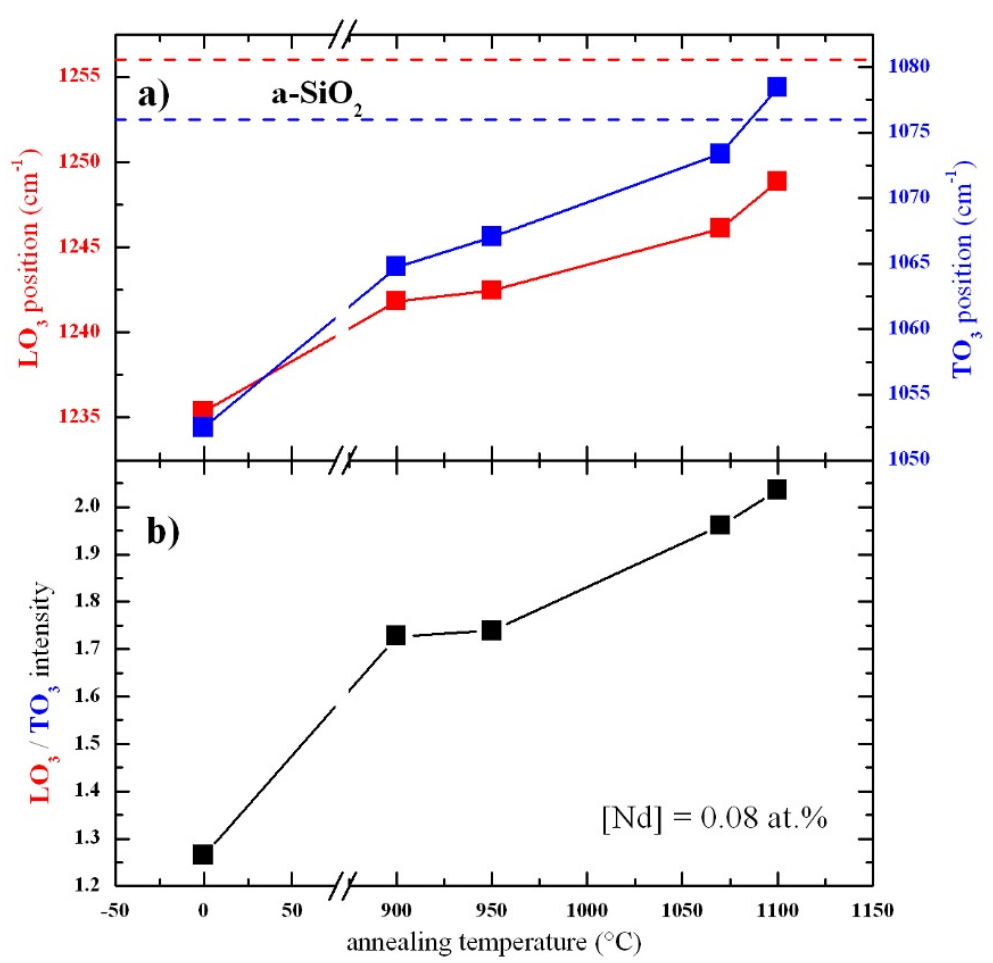

Figure 2 Evolutions of the positions of the $\mathrm{LO}_{3}$ and $\mathrm{TO}_{3}$ peaks, and the $\mathrm{LO}_{3} / \mathrm{TO}_{3}$ intensity ratio, as a function of the annealing temperature. 


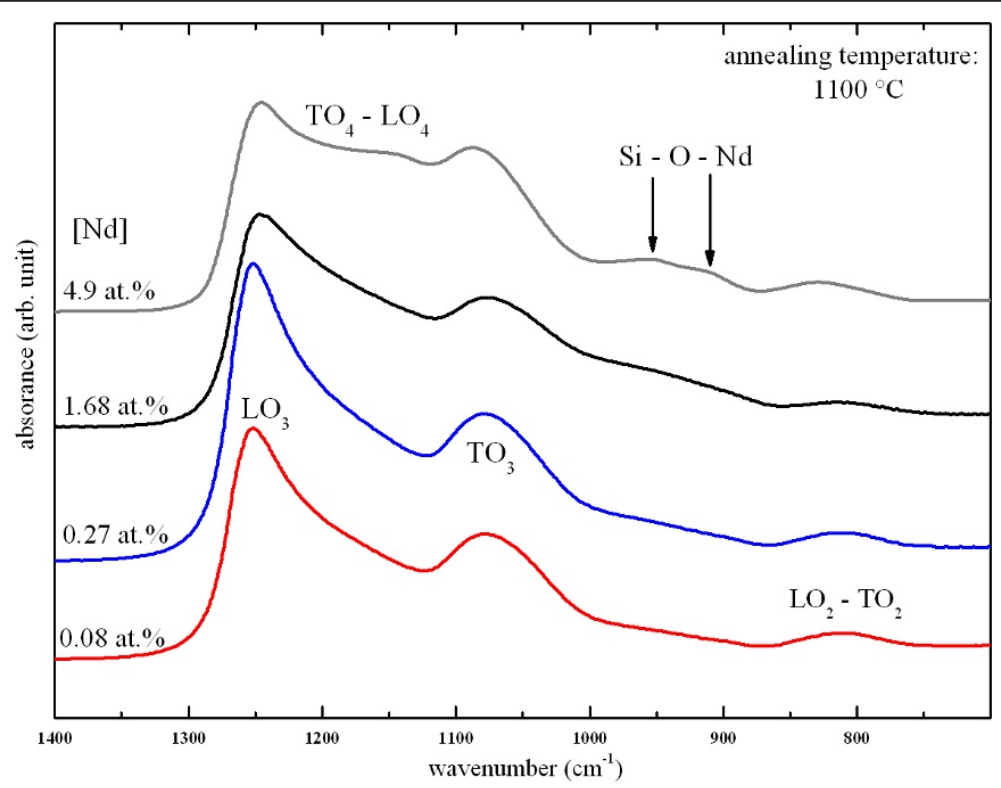

Figure 3 Evolution of the FTIR spectra as a function of the Nd concentration.

centered at $29^{\circ}$. This peak, and the $48^{\circ}$ one, indicate the presence of nanocrystalline $\mathrm{Si}[21,25]$, while the sharp and intense peaks located at $27.6^{\circ}, 28.8^{\circ}$, and $30.7^{\circ}$ are assigned to $\mathrm{Nd}_{2} \mathrm{O}_{3}$ crystals. However, the $28.8^{\circ}$ peak may result from both crystalline $\mathrm{Si}$ and $\mathrm{Nd}_{2} \mathrm{O}_{3}$. It is interesting to note that the $27.6^{\circ}$ and $30.7^{\circ}$ peaks fairly concur with the ones observed in neodymia-silica composites containing $\mathrm{Nd}_{2} \mathrm{O}_{3}$ nanocrystals by several groups $[2,3]$. As a consequence, the presence of $\mathrm{Nd}_{2} \mathrm{O}_{3}$ and $\mathrm{Si}$ nanocrystals in the highest Nd-doped sample is established, while no crystalline phases are detected in the low Nd-doped one.

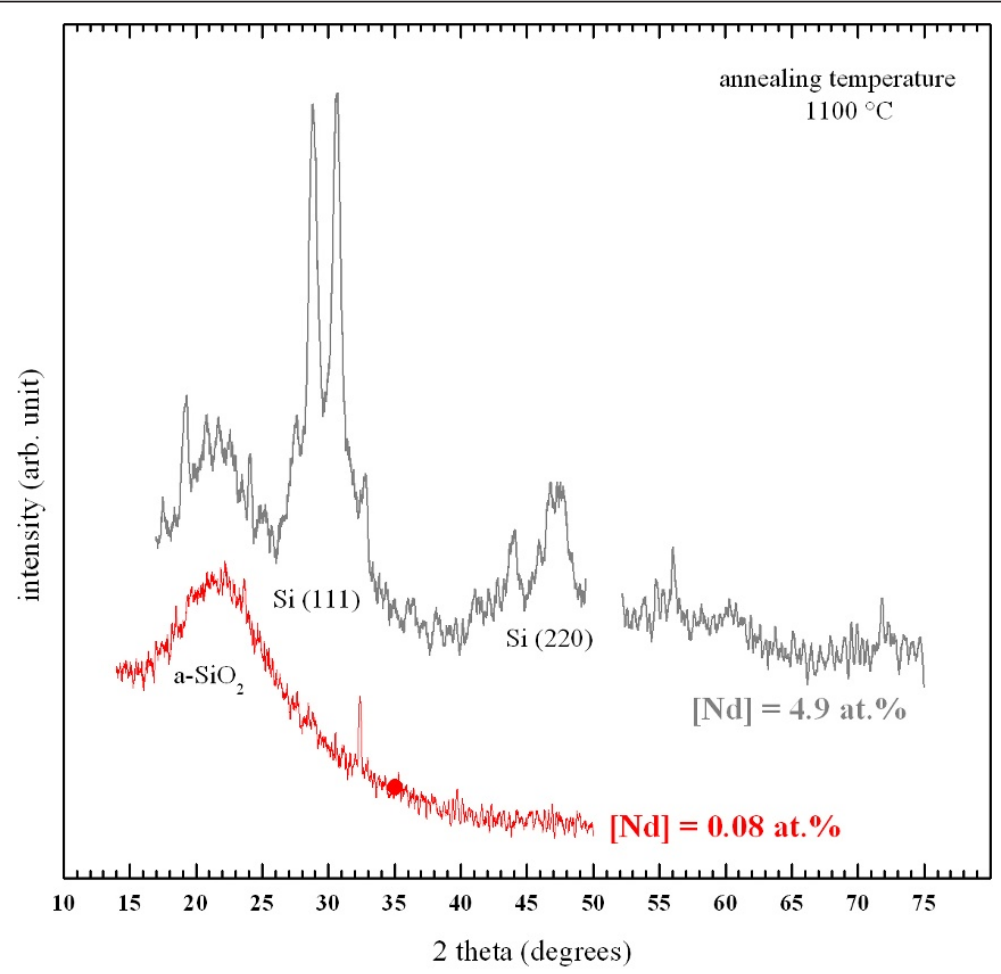

Figure 4 XRD patterns of the highest and lowest Nd-doped samples annealed at $1100{ }^{\circ} \mathrm{C}$. 
Figure 5 shows the HRTEM images of the two latter samples investigated by XRD after annealing at $1100{ }^{\circ} \mathrm{C}$. In the image of the sample with the highest $\mathrm{Nd}$ concentration of 4.9 at.\% (Figure 5a), one can recognize small Si nanocrystals because of the lattice fringes corresponding to the $\mathrm{Si}$ crystalline feature, while no crystalline structure was observed in the images of the film containing the lowest $\mathrm{Nd}$ concentration of 0.08 at.\% (Figure $5 \mathrm{~b})$. These two images are in accordance with the XRD results (see Figure 4). However, one cannot exclude that the lowest Nd-doped sample could small contain amorphous Si-np.

\section{PL spectroscopy}

Figure 6 shows the PL spectrum of the lowest Nd-doped sample after annealing at $1100{ }^{\circ} \mathrm{C}$. In the visible domain, one can observe a broad PL band that is originating from quantum-confined excitonic states in small Si-np, while in the infrared domain, three peaks centered at around 920, 1100, and $1350 \mathrm{~nm}$ are distinguishable and

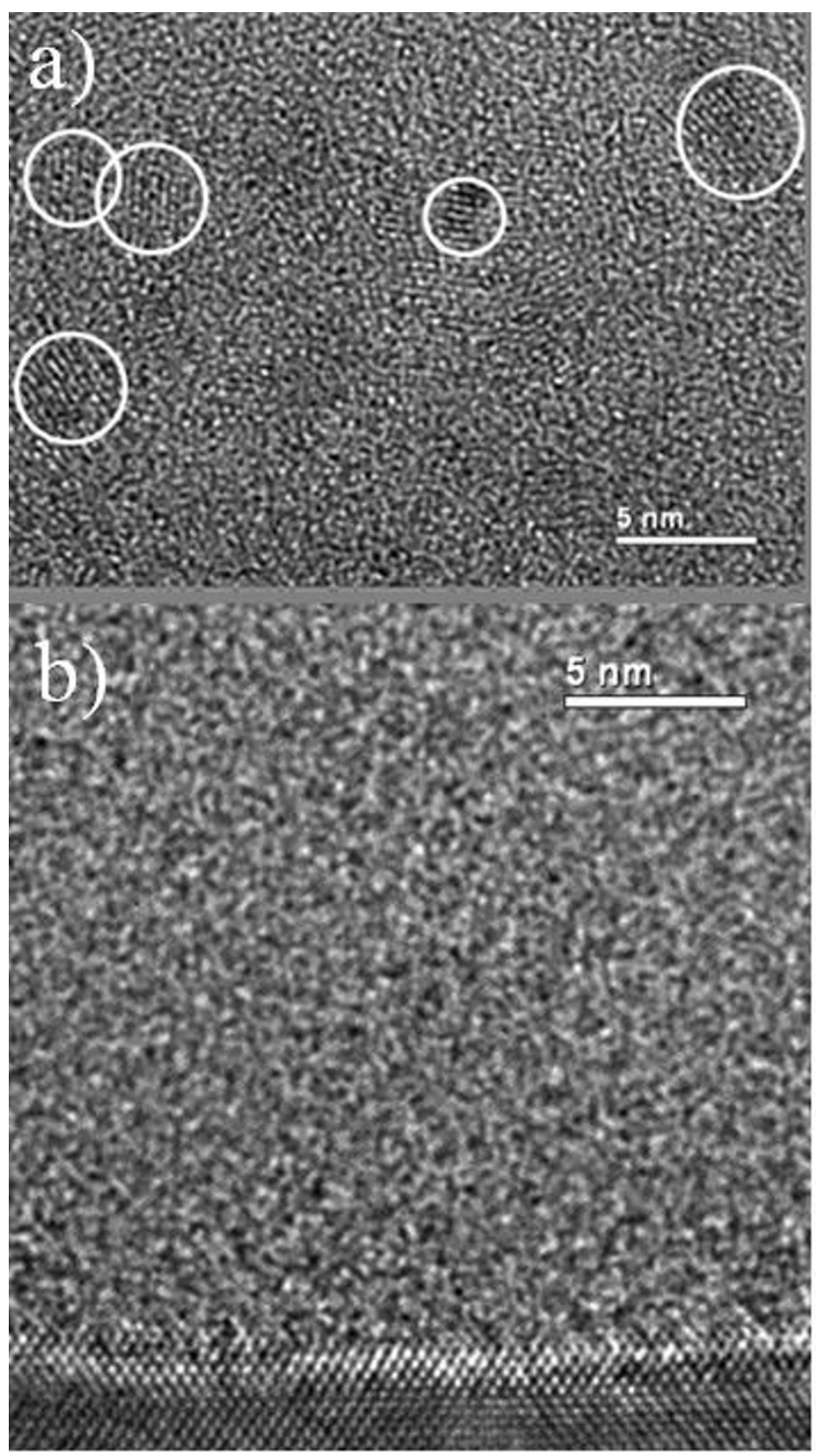

Figure 5 HRTEM images of the highest (a) and lowest (b) Nd-doped samples annealed at $1100{ }^{\circ} \mathrm{C}$ 
are attributed to the infra- $4 f$ shell transitions of $\mathrm{Nd}^{3+}$ ions from the ${ }^{4} F_{3 / 2}$ level to the ${ }^{4} I_{9 / 2},{ }^{4} I_{11 / 2}$, and ${ }^{4} I_{13 / 2}$ levels, respectively. The presence of the PL of $\mathrm{Nd}^{3+}$ ions after non-resonant excitation brings to light the sensitizing effect of Si-np towards $\mathrm{Nd}^{3+}$ ions.

The evolution of the integrated PL intensity of the Sinp PL band and the 920-nm PL peak is shown in the inset of Figure 6. The enhancement of the PL intensity of the broad visible PL band with the annealing temperature is characteristic for $\mathrm{Si}-\mathrm{np}$ embedded in $\mathrm{SiO}_{2}$. It is due to the increase of the $\mathrm{Si}$-np density, as shown by the increase of the $\mathrm{LO}_{3}$ band intensity in the FTIR spectra (see Figure 2) [21], as well as the improvement of their passivation [26] and the decrease of disorder in the host matrix. The latter is a source of non-radiative recombination channels. Interestingly, one can observe that the evolution of the PL intensity of $\mathrm{Nd}^{3+}$ ions as a function of the annealing temperature is manifestly correlated with the one of Si-np. Reminding that the PL measurements were done under non-resonant excitation, this behavior underlines the strong coupling between $\mathrm{Si}$-np and $\mathrm{Nd}^{3+}$ ions, and, accordingly, the potential of sensitizing of Si-np. The increase of the PL intensity of $\mathrm{Nd}^{3+}$ is then explained by the increase of the Si-np density as well as the increase of non-radiative de-excitation channels of both Si-np and $\mathrm{Nd}^{3+}$. The $\mathrm{Nd}^{3}$ + PL intensity is then maximal after annealing at $1100{ }^{\circ} \mathrm{C}$ which is generally admitted as the optimal annealing temperature for the PL of Si-np.

Figure 7 shows the behavior of the PL spectra of the thin films annealed at $1100{ }^{\circ} \mathrm{C}$ as a function of the $\mathrm{Nd}$ concentration. As the $\mathrm{Nd}$ content increases from 0.08 to
0.27 at.\%, the PL intensity of Si-np drastically drops and disappears at 1.68 at.\%. Then, PL of Si-np surprisingly reappears at the highest $\mathrm{Nd}$ concentration of 4.9 at.\%. Interestingly, one can observe that the positions and widths of the PL peaks of the two lowest $\mathrm{Nd}$-doped samples remain identical (see the inset); whereas the PL peak of the highest Nd-doped film is manifestly shifted to longer wavelengths. According to the quantum confinement model, the PL of the latter sample therefore emanates from $\mathrm{Si}$-np that are sensibly larger than the ones present in the two former samples. In the infrared spectral domain, one can observe that the PL intensity of $\mathrm{Nd}^{3+}$ ions drops progressively with increasing $\mathrm{Nd}$ concentration.

\section{Discussion}

During the annealing, a phase separation occurs as demonstrated in the FTIR spectra in Figure 1, leading to the condensation of Si-np that were detected by XRD (see Figure 4) and HRTEM (see Figure 5). Besides, the presence of Si-np in the films was confirmed by the occurrence after annealing of a 740-nm broad PL band that is characteristic for Si-np.

The presence of PL of $\mathrm{Nd}^{3+}$ ions under non-resonant excitation evidenced the efficient energy transfer between $\mathrm{Si}$-np and $\mathrm{Nd}^{3+}$ ions (Figure 6). The concentration quenching of the PL of $\mathrm{Nd}^{3+}$ ions that was observed in Figure 7 is partly explained by cross relaxation processes between $\mathrm{Nd}^{3+}$ ions and neighboring $\mathrm{Nd}^{3+}$ ions and/or $\mathrm{Nd}_{2} \mathrm{O}_{3}$ nanocrystals as reported in glass matrices $[4,5]$. This is supported by the existence of $\mathrm{Nd}_{2} \mathrm{O}_{3}$ nanocrystals in the highest $\mathrm{Nd}$-doped sample

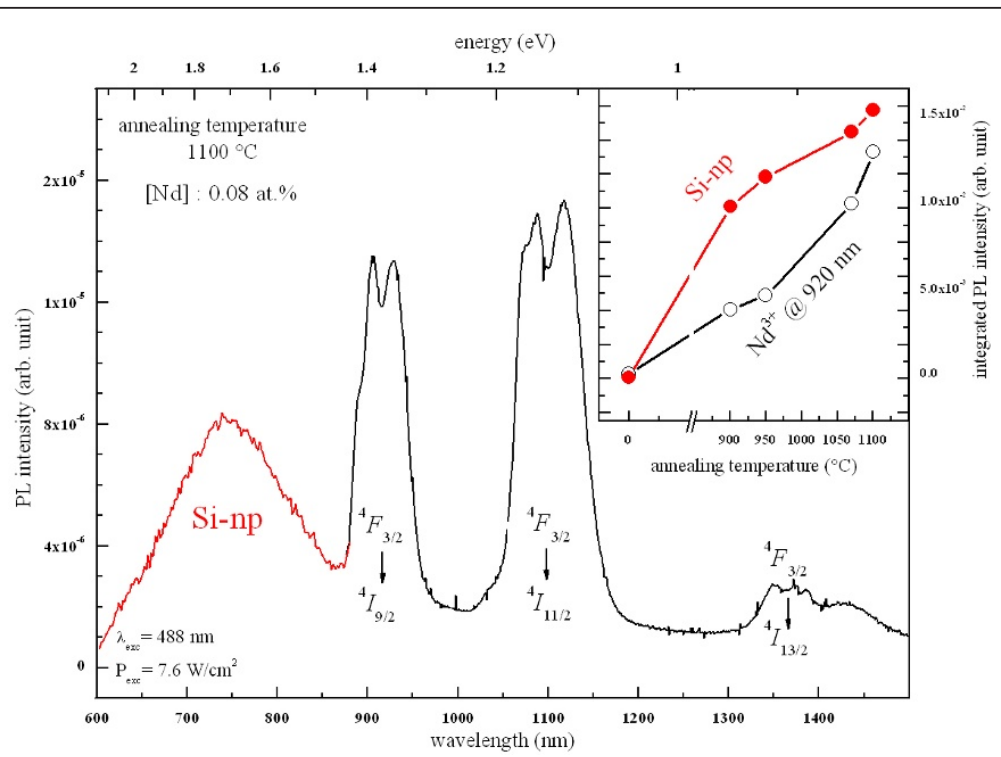

Figure $6 \mathrm{PL}$ spectrum of the lowest Nd-doped sample annealed at $1100^{\circ} \mathrm{C}$. (Inset) Evolutions of the integrated PL intensity of the Si-np PL band and the first $\mathrm{Nd}^{3+}$ ions PL peak as a function of the annealing temperature. 


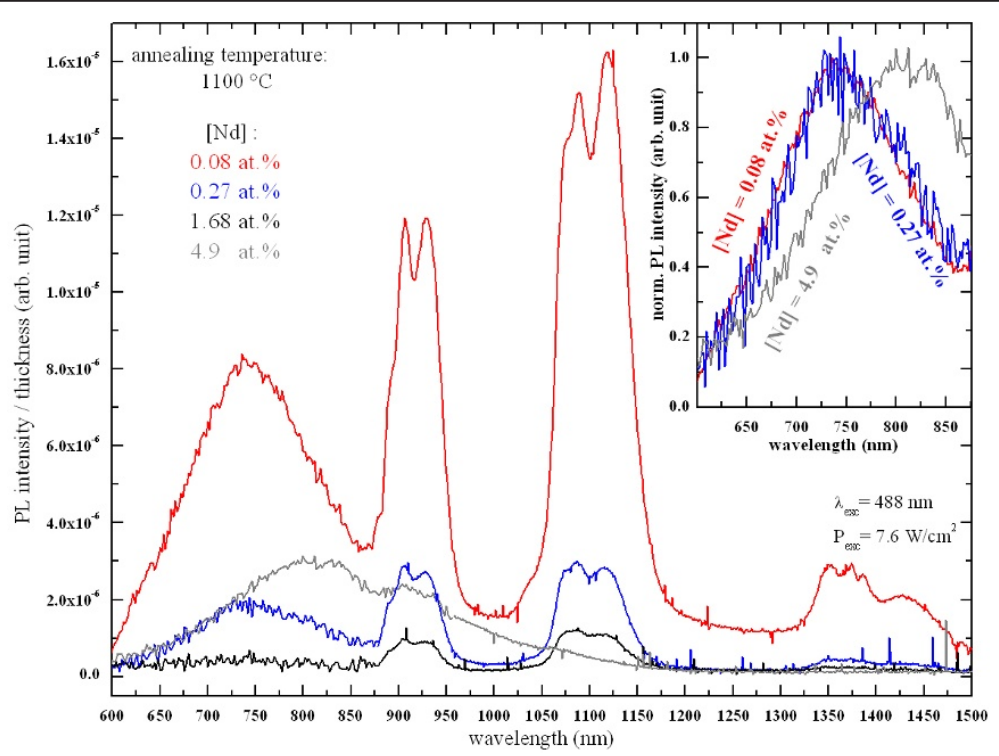

Figure 7 Evolution of the PL spectra as a function of the $\mathrm{Nd}$ concentration.

(see Figure 4). Besides, non-radiative channels inherent to disorder induced by the $\mathrm{Nd}$ incorporation (see Figure 3) can be in competition with the energy transfer mechanism between Si-np and $\mathrm{Nd}^{3+}$ ions in such nanocomposite systems leading to the common decrease of the PL intensity of $\mathrm{Nd}^{3+}$ and $\mathrm{Si}-\mathrm{np}$. As a consequence, the emission of $\mathrm{Nd}^{3+}$ ions is more efficient while Si-np are formed, and while the $\mathrm{Nd}$ content is low (0.08 at.\%). In such conditions, $\mathrm{Nd}^{3+}$ ions benefit from the sensitizing effect of Si-np and from the weak competition of non-radiative recombinations in the host matrix. The decrease of the PL of Si-np with increasing $\mathrm{Nd}$ content ranging from 0.08 to 4.9 at.\% (Figure 7 ) is explained by the raise of energy transfer between $\mathrm{Si}-\mathrm{np}$ and $\mathrm{Nd}^{3+}$ ions (which can be luminescent or not), and by the increase of non-radiative recombinations provided by the increase of disorder as shown in Figure 3. Besides, the presence of a $\mathrm{Nd}_{2} \mathrm{O}_{3}$ phase in the host matrix at the highest $\mathrm{Nd}$ content significantly modifies the number of oxygen atoms available to form the silicon oxide host matrix consequently leading to the formation of larger Si-np with a higher density. Besides, the formation of $\mathrm{Nd}_{2} \mathrm{O}_{3}$ nanocrystals results in the rise of the average interaction distance between $\mathrm{Si}-\mathrm{np}$ and $\mathrm{Nd}$ atoms (agglomerated or not) leading to the occurrence of notcoupled Si-np, which therefore enables emission of light in the visible range. This explains the presence of the PL peak of Si-np in the highest Nd-doped sample (Figure 7) which is significantly shifted to longer wavelengths. The fact that XRD pattern of Si nanocrystals, were detected in the latter sample and not in the lowest Nd-doped sample (Figure 4) may also be attributed to the modification of the Si-np size and density.

\section{Conclusion}

The relationships between the composition, the microstructure, and the PL properties of Nd-doped SRSO thin films that contain the same Si excess were studied. We could establish that the maximum of the PL intensity of $\mathrm{Nd}^{3+}$ ions was obtained after annealing at $1100{ }^{\circ} \mathrm{C}$ which corresponds to the better situation for the achievement of highly luminescent Si-np embedded in $\mathrm{SiO}_{2}$, i.e., containing a small quantity of non-radiative recombination channels. It was demonstrated that the PL of $\mathrm{Nd}^{3+}$ ions was quenched at high $\mathrm{Nd}$-concentration (4.9 at.\%) because of the formation of $\mathrm{Nd}_{2} \mathrm{O}_{3}$ nanocrystals and the occurrence of disorder in the host matrix. The former participates in the concentration quenching mechanism because of cross relaxation processes, while the latter induces the occurrence of new non-radiative channels which are in competition with the energy transfer mechanism between Si-np and $\mathrm{Nd}^{3+}$ ions.

\section{Abbreviations}

FTIR: Fourier transform infrared; LO: longitudinal optical; PL: photoluminescence; RE: rare earth; Si-np: silicon nanoparticles; SRSO: siliconrich silicon oxide; TO: transverse optical; XRD: X-ray diffraction.

\section{Acknowledgements}

The authors are grateful to the French Agence Nationale de la Recherche, which supported this study through the Nanoscience and Nanotechnology program (DAPHNES project ANR-08-NANO-005).

\section{Authors' contributions}

OD fabricated the thin films and carried out the optical and microstructural characterizations. XP investigated the films by HRTEM. JC made significant contribution to the optical properties. FG conceived of the study and participated in the coordination and writing of the manuscript. All authors read and approved the final manuscript. 


\section{Competing interests}

The authors declare that they have no competing interests.

Received: 24 September 2010 Accepted: 21 February 2011

Published: 21 February 2011

\section{References}

1. Kenyon AJ: Recent developments in rare-earth doped materials for optoelectronics. Prog Quant Electron 2002, 26:225.

2. Kępiński L, Zawadzki M, Miśta W: Hydrothermal synthesis of precursors of neodymium oxide nanoparticles. Solid State Sci 2004, 6:1327.

3. Lal B, Kumar S, Aghamkar P, Rohilla S, Singh D: Structural studies of annealed neodymia-silica composite synthesized by solgel technique. Physica B 2009, 404:3452.

4. Caird JA, Ramponi AJ, Staver PR: Quantum efficiency and excited-state relaxation dynamics in neodymium-doped phosphate laser glasses. JOSA B 1991, 8:1392.

5. Jacinto C, Oliveira SL, Nunes LAO, Myers MJ, Catunda T: Normalizedlifetime thermal-lens method for the determination of luminescence quantum efficiency and thermo-optical coefficients: Application to $\mathrm{Nd} 3$ +-doped glasses. Phys Rev B 2006, 73:125107.

6. Kenyon AJ, Trwoga PF, Federighi M, Pitt CW: Optical properties of PECVD erbium-doped silicon-rich silica: evidence for energy transfer between silicon microclusters and erbium ions. J Phys Condens Matter 1994, 6:L319.

7. Franzo G, lacona F, Vinciguerra V, Priolo F: Enhanced rare earth luminescence in silicon nanocrystals. Mater Sci Eng B 2000, 69-70:335.

8. Gourbilleau F, Levalois M, Dufour C, Vicens J, Rizk R: Optimized conditions for an enhanced coupling rate between Er ions and Si nanoclusters for an improved 1.54- $\mu \mathrm{m}$ emission. J Appl Phys 2004, 95:3717.

9. Franzó G, Vinciguerra G, Priolo F: The excitationmechanism of rare-earth ions in silicon nanocrystals. Appl Phys A Mater Sci Process 1999, 69:3.

10. Watanabe K, Tamaoka H, Fujji M, Moriwaki K, Hayashi S: Excitation of Nd3+ and Tm3+ by the energy transfer from Si nanocrystals. Physica E 2002, 13:1038.

11. Seo SY, Kim M-J, Shin J: The Nd-nanocluster coupling strength and its effect in excitation/de-excitation of $\mathrm{Nd} 3+$ luminescence in $\mathrm{Nd}$-doped silicon-rich silicon oxide. Appl Phys Lett 2003, 83:2778.

12. MacDonald AN, Hryciw A, Lenz F, Meldrum A: Interaction between amorphous silicon nanoclusters and neodymium ions. Appl Phys Lett 2006, 89:173132

13. Bréard D, Gourbilleau F, Dufour C, Rizk R, Doulan J-L, Camy P: Spectroscopic studies of $\mathrm{Nd} 3+-$ doped silicon-rich silicon oxide films. Mater Sci Eng 2008, 146:179.

14. Bréard D, Gourbilleau F, Belarouci A, Dufour C, Rizk R: Nd3+ photoluminescence study of $\mathrm{Nd}$-doped Si-rich silica films obtained by reactive magnetron sputtering. J Lumin 2006, 121:209.

15. Gourbilleau F, Belarouci A, Bréard D, Dufour C, Rizk R: Active emitters based on nanostructured Si. Int J Nanotechnol 2008, 5:574.

16. Podhorodecki A, Misiewicz J, Gourbilleau F, Cardin J, Dufour C: High Energy Excitation Transfer from Silicon Nanocrystals to Neodymium lons in Silicon-Rich Oxide Film. Electrochem Solid State 2010, 13:K26-K28.

17. Ternon C, Gourbilleau F, Portier X, Voivenel P, Dufour C: An original approach for the fabrication of $\mathrm{Si} / \mathrm{SiO} 2$ multilayers using reactive magnetron sputtering. Thin Solid Films 2002, 419:5.

18. Hinds BJ, Wang F, Wolfe DM, Hinkle CL, Lucovsky G: Study of SiOx decomposition kinetics and formation of Si nanocrystals in an $\mathrm{SiO} 2$ matrix. J Non-Cryst Solids 1998, 227-230:507.

19. Ono $H$, Ikarashi $T$, Ando $K$, Kitano $T$ : Infrared studies of transition layers at SiO2/Si interface. J Appl Phys 1998, 84:6064.

20. Charvet S, Madelon R, Gourbilleau F, Rizk R: Spectroscopic ellipsometry analyses of sputtered Si/SiO2 nanostructures. J Appl Phys 1999, 85:4032.

21. Gourbilleau F, Dufour C, Levalois M, Vicens J, Rizk R, Sada C, Enrichi F, Battaglin G: Room-temperature $1.54 \mu \mathrm{m}$ photoluminescence from Erdoped Si-rich silica layers obtained by reactive magnetron sputtering. J Appl Phys 2003, 94:3869.

22. Ono H, Katsumata T: Interfacial reactions between thin rare-earth-metal oxide films and Si substrates. Appl Phys Lett 2001, 78:1832.

23. Fidalgo A, Ilharco LM: The defect structure of sol-gel-derived silica/ polytetrahydrofuran hybrid films by FTIR. J Non-Cryst Solids 2001, 283:144.

24. Innoncenzi P: Infrared spectroscopy of sol-gel derived silica-based films: a spectra-microstructure overview. J Non-Cryst Solids 2003, 316:309.
25. Kapaklis V: Structural characterization of silicon nanocrystals from amorphous silicon oxide materials. J Non-Cryst Solids 2008, 354:612.

26. Garrido B, López M, Pérez-Rodríguez A, García C, Pellegrino P, Ferré R, Moreno JA, Morante JR, Bonafos C, Carrada M, Claverie A, de la Torre J, Souifi A: Optical and electrical properties of Si-nanocrystals ion beam synthesized in SiO2. Nucl Instrum Meth. B 2004, 216:213.

doi:10.1186/1556-276X-6-161

Cite this article as: Debieu et al.: Effect of the Nd content on the structural and photoluminescence properties of silicon-rich silicon dioxide thin films. Nanoscale Research Letters 2011 6:161.

\section{Submit your manuscript to a SpringerOpen ${ }^{\mathcal{O}}$ journal and benefit from:}

- Convenient online submission

- Rigorous peer review

- Immediate publication on acceptance

- Open access: articles freely available online

- High visibility within the field

- Retaining the copyright to your article

Submit your next manuscript at $\mathbf{s p r i n g e r o p e n . c o m ~}$ 